\title{
Environmental Sensitive Area (ESA) for Route Selection of Transmission Tower
}

\author{
M.S. Zulkarnain ${ }^{1}$, R.C. Omar ${ }^{2}$, I.N.Z. Baharuddin², R. Roslan², S.A. Kamarudin ${ }^{2}$ \\ ${ }^{I}$ College of Graduate Studies, Universiti Tenaga Nasional \\ ${ }^{2}$ Institute of Energy Infrastructure, Universiti Tenaga Nasional \\ *Corresponding author E-mail: syamzari87@gmail.com
}

\begin{abstract}
Transmission route selection needs to determine in order to have the best route for the transmission line. This paper presents a few alternative transmission line routes together by using cost path analysis application, minimizing and avoiding propose new located tower in landslide hazard area. The conventional route planning method usually only take into considerations of topographical such as gradient and curvature. This method unable to sustain the environment. This study can take into consideration of many factors that related to Environmental Sensitive Area (ESA) such as prone to landslide area, forestry area, land cover and land use. Different influence factor that assign to the weightage will resulted to different output of the suitability map. This study will have used nine Environmental Sensitive Area (ESA) factors, and using three difference influence factors that will optimize the result of the suitability map.
\end{abstract}

Keywords: Environmental; Intelligent; Landslide; Sensitive; Transmission.

\section{Introduction}

The purpose of Environmental Sensitive Area (ESA) Safe and Intelligent Transmission Route Finder (ESASIRF) for transmission line is to generate a few alternative transmission line routes by using cost path analysis, by using this analysis, it can minimize the propose location tower that situated in landslide risk prone area, and can spot the tower in best cost area and avoid landslide risk area. These study will provide safe, reliable electrical service to its customers in Kelantan in the most efficient and cost-effective manner. The new transmission line and substation will also provide improved operational flexibility in conjunction with future generation resources especially in utilities planning.

The traditional route planning method usually has been based on topographical considerations. This approach is unable to take into consideration of other factors. Geographic Information Systems (GIS) in planning react as an important technology to integrating and analyzing a large amount of geospatial data. [1,2,3] and [4]. With the mass development, it is very important to plan the uitilities and transportation in order to achive beneficial economic,social and environmental effects [5].

Since 1980's, GIS integrate with multi criteria decision making method has helped in planning process [6]. By using the GIS technology and multi criteria decision making method, its helps in comparison of diferrent criteria, and also in the planning process and decision making in conflicting decisions. The application of GIS and multi criteria decision making has helped as a guide for decision makers towards actualizing a desired choice in making a decision [7]. In order to make route path planning and evaluation operational, they must be conveyed to decision makers in the most efficient and transparent way.By using GIS technology and multicriteria analysis in decision making has helped the decision makers in solving problems. This means that the framework adopted during the evaluation must be made explicit so as to allow tracking of the influence of each factor on the evaluation results. This is optimally achieved with the use of GIS and multi criteria decision making [8].

In Geographical Information Sytems (GIS), the techniques for determine the best solution for the routing of power lines and other linear infrastructures is by using least cost path analysis (LCPA). LCPA analysis can help the user to find the cheapest path from one point to another point through a cost surface that generated from the GIS.The cost surface is represented by a raster map in which each cell is given a cost that defines how "expensive" it is to pass through that cell. LCPA can be process by generating an accumulated cost surface, on which a route can be determine that goes from a starting point to the destination point [9]. The accumulated cost surface is generated from the cost surface, by calculating the cumulative cost of each cell from the starting point. The procedure is performed by an algorithm that searches, among the starting pointe's neighbouring cells, that with the lowest value. The selected cell now becomes a starting point and its neighbouring cells are checked to identify the one with the lowest value.

The least cost path analysis between the starting point and the destination point is accumulated by using cost surface analysis, the analysis choosing cells at decreasing value [10]. After [11] somel algorithms have been proposed for the implementation of LCPA in raster-based GIS [12,13]. All criteria that affect the selection of the routing is calculated by using the cost surface analysis through a multicriteria evaluation [14]. To minimise the impacts caused by the construction and the operation of the infrastructure .The criteria should reflect the objectives of the designers.

In order to achieve beneficial economic, social and environmental outcomes the environmental sensitive area concepts that have been introduced as part of development consideration in Malaysia will be integrated in this paper. The selection of the route planning will be combined with landslide susceptibility mapping (LSM) for 
the prediction of future hazard, decision making and hazard mitigation planes [15]. LS modeling is divided to two methods which are qualitative and quantitative methods. The degree of objectivity shows the differences of this both methods.

The qualitative methods depend on the knowledge and previous experience of the experts, [16] and the use of index or parameter maps $[17,18]$. The quantitative methods is on the relationships between conditioning factors and landslide occurrence accordingly on the numerical index,geotechnical engineering approaches $[19,20]$, statistical analysis $[21,22,23]$, as well as new interesting approaches of LS assessment such as artificial neural network (ANN) and neuro-fuzzy logic methods [24,25]. Some qualitative approaches however incorporate the idea of ranking and weighting the parameters involved, and may turn to be semi-quantitative in nature $[26,27]$. The use of quanlitative methods should not be seen as an easier option than the quantitative methods. Qualitative methods are of value where the available resources or data dictate that more formalized quantitative assessment would be inappropriate or impractical [28]. It is also worth emphasizing the quality of a landslide risk assessment, is related to extend of hazards are recognized, understood, and explained, which is not necessarily, related to the extent to which they are quantified [29]. The concept the have been explained through literature review give some outline to author for the guidance of minimising the risk in development planning of transmission route and managing the asset from the landslide risk. Based on that, these paper will present the potential of integrated system using Geographical Information System (GIS) technology to devise an intelligence approach for route planning in that particular environmental sensitive area especially the area prone to landslides. This environmental sensitive area (ESA) safe and intelligent route finder (ESASIRF) for transmission line can generate a few alternative transmission line routes within a corridor alongside a cost path analysis application, minimizing located tower in landslide risk prone area and adding tower spotting capabilities in best cost and low landslide risk.

\section{Methodology}

The GIS based approaches for route selection is important to determine the affecting factors to utilize the relative rankings and weights. The area that involves the proposed route should be limited and identified for collecting and assembling the data of the area. Fig. 1 shows the schematic representation of the methodology. Each of the components has been discussed in detail.

\subsection{Selection of Factors Affecting the Route and Land- slide Hazard}

The first step in routing process is the selection of spatial and nonspatial factors affecting the transmission route. When a new routing process is initiated, the list of multiple variables has to be decided first and then the criteria by which these variable constraint the routing process. The criteria refer to the rules which the route should abide to. In general the following factors were found to be more important and are addressed in greater detail in this work are avoid areas with steep slopes, avoid road crossings, but proximity to the roads should be high, avoid railway crossings, avoid river crossings, avoid prohibited areas (cities, towns, reservoirs), avoid reserved forest areas, avoid areas with high land cost and avoid unfavorable soil type.

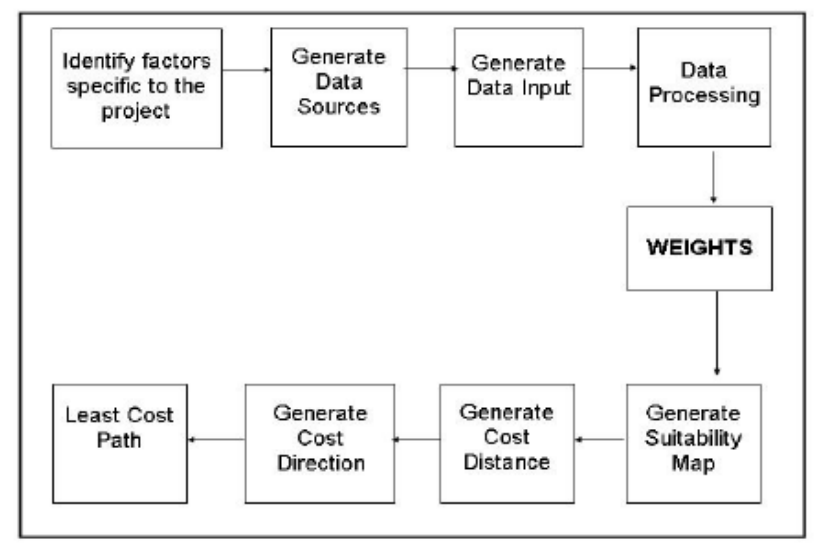

Fig. 1: The schematic representation of methodology

\subsection{Data Sources}

In this study,there area 6 types of data have been selected as the conditioning factors on landslide susceptibility.This data is selected based on the avaibility of the data and the nature of the study area.Elevation, slope, aspect, precipitation, lithology and land cover consist of continuous data, all this data need to be classified into five clases. The others data that been used in this study is elevation, slope, river, existing transmission line and road.

\subsection{Data Processing}

The analysis contains three main stages which are for land use purpose, analysis method in order to meet the land use purpose and acceptance purpose result of analysis after confirmation of the system. Basic assessment is used to assess relationship between land use site suitability factor for each environment need for the development and the conservation will affect that development. The criteria value in every level of hierarchy is based on the comparison matrix. Weighting factor for every criterion is different according to its need and counted as normalization component. This process will be repeated at every level hierarchy.

A weighting system has to be devised for weighing each of the map layers to develop different route. The weighting system forms the backbone of the methodology. The weighted layers are all summed up to form suitability layer. As mention, different weighting ratings are assigned to develop different route according to the client's priority and the type of land use or land involved. Lower rating indicated the most preferred route for the route selection and vice versa. This weighting system can also be assigned by referring to the type of land use or land involved. It is known that compensation cost of rubber estate area is higher than secondary forest. If the compensation cost is higher, the area is less preferred and a higher rating will be assigned according to the weighting system. Beside the cost of the land, the weighting also be refer to the landslide risk which the risk of landslide must be lower to reduce the construction and maintenance cost. The multicriteria decision making has been used to derive weightages for the thematic layers. The suitability layer is analyzed for the optimal route. Every factor divided into 6 key major parameter and sub-parameter that analyzed using six scale namely 5 (high), 4 (medium height), 3 (medium), 2 (medium low), 1 (low) and 0 (unlisted) to calculate the degree of impact (Vi) for each parameter. Regional analysis assessment is used to determine landslides hazard zonnation by extracting relevant parameters from remote sensing image. Valuable parameters such as land use zone, lithology, lineament (geological structure), groundwater level, weather condition (precipitation), vegetation cover, topography and geomorphology are determined based on satellite imagee and secondary measured data. Each of the parameters layers will be transferred to ArcGIS to develop the layer for geohazard zonnation and risk assessment especially for landslide and factor 
of safety. GIS application for the slope stability analysis of an area refers to the hazard zonations, which are basically the division of land surface into areas and ranking of these areas according to degree of actual or potential hazard of landslide or other mass movement on a map displaying them spatial distribution of the hazard classes. Generally the factor of safety for slope failure in regional scale are commonly using the infinite slope method that can be simplified and can be easily applied for preparing the hazard zonation. It is essential to understand the forces acted on slopes which is the driving force and the resisting force which prevent the slope failing. FOS is the ratio of resisting forces to driving forces. In these particular reasons, parameter as Table 1 and FOS equation is used and are analysed using geographic information system.

$$
\text { FOS }=\frac{\mathrm{C}+\left(\gamma-\mathrm{m} \gamma_{\mathrm{W}}\right) \mathrm{Z} \cos \beta \cos \beta \tan \phi}{\gamma \mathrm{Z} \sin \beta \cos \beta}
$$

Table 1: The variable definitions, units and probable value ranges.

\begin{tabular}{|c|c|c|c|}
\hline Symbol & Definition & Units & $\begin{array}{l}\text { Value } \\
\text { Range }\end{array}$ \\
\hline $\mathrm{C}$ & Cohesion & $\mathrm{kN} / \mathrm{m}^{2}$ & $0-250$ \\
\hline$\Gamma$ & Unit weight of slope material & $\mathrm{kN} / \mathrm{m}^{3}$ & $12-22$ \\
\hline$\gamma_{\mathrm{w}}$ & Unit weight of water & $\mathrm{kN} / \mathrm{m}^{3}$ & 9.81 \\
\hline Z & $\begin{array}{l}\text { Thickness of slope material above } \\
\text { the slide plane }\end{array}$ & $\mathrm{m}$ & $1-20$ \\
\hline$Z_{w}$ & $\begin{array}{l}\text { Thickness of saturated slope } \\
\text { material above the slide plane }\end{array}$ & $\mathrm{m}$ & $0-20$ \\
\hline $\mathrm{m}$ & $\begin{array}{c}\text { Vertical height of water table } \\
\text { above the slide plane, expressed as } \\
\text { a fraction of total thickness }\end{array}$ & dimensionless & $0-1$ \\
\hline B & $\begin{array}{l}\text { Slope of the ground surface which } \\
\text { is assumed parallel to the slope of } \\
\text { the failure plane }\end{array}$ & degrees & $1-40$ \\
\hline$\varnothing$ & Internal angle of friction & degrees & $22-46$ \\
\hline $\mathrm{S}$ & Shear strength & $\mathrm{kN} / \mathrm{m}^{2}$ & \\
\hline $\mathrm{T}$ & Shear stress & $\mathrm{kN} / \mathrm{m}^{2}$ & \\
\hline$\Sigma$ & Normal stress & $\mathrm{kN} / \mathrm{m}^{2}$ & \\
\hline $\mathrm{M}$ & Pore water pressure & $\mathrm{kN} / \mathrm{m}^{2}$ & \\
\hline
\end{tabular}

Dijkstra's algorithm are used in routing process. For a given source vertex (node), the algorithm finds the path with lowest cost (i.e. the shortest path) between that vertex and every other vertex. It can also be used for finding costs of shortest paths from a single vertex to a single destination vertex by stopping the algorithm once the shortest path to the destination vertex has been determined. For example, if the vertices represent cities and edge path costs represent driving distances between pairs of cities connected by a direct road, Dijkstra's algorithm can be used to find the shortest route between one city and all other cities. As a result, the shortest path first is widely used in network routing protocols, most notably IS-IS and OSPF (Open Shortest Path First).

Data processing will be process based on factor that will affected the route. Fig. 2 shows the process for generating features map such as road, forest, towns, slope and land cost. The process involving the converting of vector data to raster data and later need to be reclassified. The result from zone of influence will be calculate landslide hazard map and cost maps.

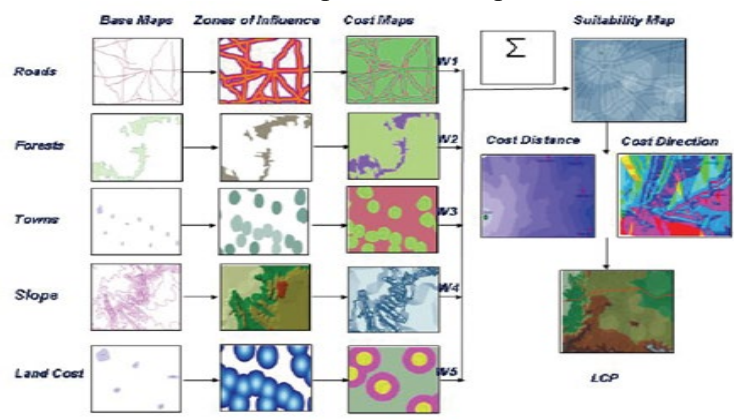

Fig. 2: Overview of layering process and generating landslide hazard map and cost map
A GIS system for analysis of route was favored because it can perform optimal route predictions based selection by incorporating multiple influence factors into its analysis. These influence factors are grouped into common viewpoints or perspectives addressing a common data theme or point of view such as landslide, slope, road and others. In this project, the weightage used to generate route is based on Table 2 which is according to client's needs and priority. A higher percentage of influence factors indicate the priority of avoiding an area with high percentage of influence. As an example, if client's priority is to avoid area with high risk of landslide, the influence factor for landslide is highest.

Table 2: Influence factor for route selection

Table 2: Influence factor for route selection
\begin{tabular}{|c|c|c|c|}
\hline Item & Route $1(\%)$ & Route $2(\%)$ & Route $3(\%)$ \\
\hline Landslide & 10 & 10 & 10 \\
\hline Slope & 9 & 5 & 10 \\
\hline Road & 8 & 10 & 5 \\
\hline River & 8 & 5 & 5 \\
\hline Railroad & 8 & 5 & 5 \\
\hline Land Use & 8 & 5 & 25 \\
\hline Elevation & 10 & 10 & 15 \\
\hline Powerline & 30 & 45 & 10 \\
\hline Cadaster & 9 & 5 & 15 \\
\hline TOTAL & 100 & 100 & 100 \\
\hline
\end{tabular}

After identifying the alternative sites, selection of the most appropriate site can be made by consideration of multi-criteria imposed based on client need. Multi-criteria decision aid supporting the choice among a set of alternatives described by values for criteria. This study has selected three types of routes in generating alternatives. Using spatial analysis model, all three types of routes will be evaluated against the set criteria in order to selecting optimum route (as Table 2). It is important to note however, that the analysis need to provide the capability to maximized the output to connecting strategic locations and maximizing network. The three proposed route alternatives are evaluated on the basis of the criteria discussed above. Decision rules provide the basis for sorting and ranking the decision alternatives under consideration of route attributes and user preferences. The application of final step for multi-criteria procedure have be presented as in Table 2 for criteria and alternatives. The decision maker selects the suitable score for each cell in the mention Table 2. The normalized sum computes the sum of all factors for each alternative. Which, the higher values are preferable than smaller values in selecting the preferred alternative.

\section{Result and Discussion}

Landslide Hazard Map (LHM) was prepared on the basis of slope map, aspect map, land use map and geological map with the help of ArcGIS using weighted overlay method. The cell size was using is $30 \mathrm{~m}$ in this study area. Slope and aspect map of the study area was developed from Digital Elevation Model (DEM). Landslide hazard map is generated in GIS software where it counts pixels and classify them into 5 classes. The 5 classes are very high risk, high, medium, low and very low risk.All paragraphs must be justified alignment. With justified alignment, both sides of the paragraph are straight

The percentage of area involve in one classes is calculated and a graph is generated using ArcGIS 10.0. Landslide map of the area varies from 1 (Very Low Risk) to 5 (Very High Risk) giving the mean landslide of 2.24 which falls into low risk of landslide. Most of the study are are classified as low in landslide risk which is $65.904 \%$ while only $0.0003 \%$ categorize as very high risk of landslide as Table 3 . This indicates that the area is suitable for any construction due to low of landslide risk. Landslide hazard map are represent as in Fig. 3. 


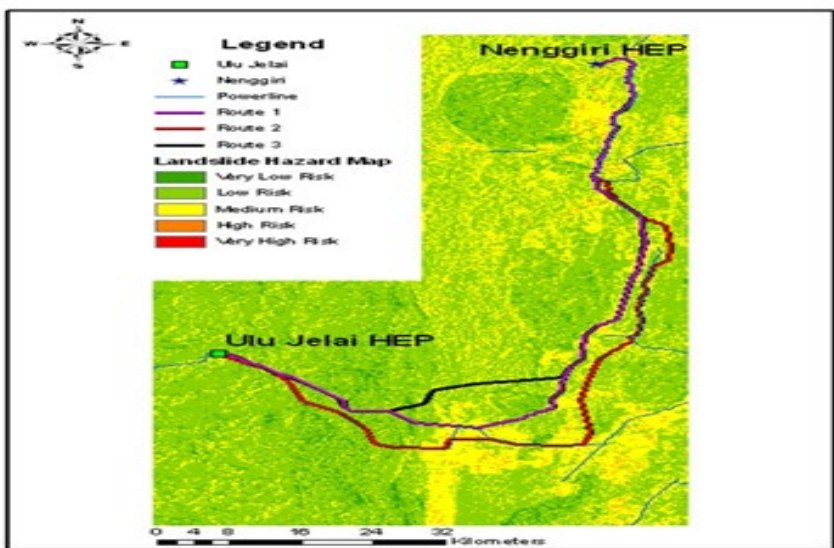

Fig. 3: Landslide Hazard Map and percentage of landslide of the study area

Table 3: Percentage of landslide risk in the study area

\begin{tabular}{|c|c|c|}
\hline Risk & Count & $\begin{array}{c}\text { Percentage } \\
(\%)\end{array}$ \\
\hline Very Low & 309118 & 5.1874 \\
\hline Low & 3930591 & 65.9604 \\
\hline Medium & 1678696 & 28.1707 \\
\hline High & 40595 & 0.6812 \\
\hline Very High & 18 & 0.0003 \\
\hline
\end{tabular}

Hence for calculation and modelling of factor of safety through geographic information system (GIS), Digital Elevation Model (DEM) was prepared from converting the TIN to raster using the cell size $30 \mathrm{~m}$ (Fig. 4). Elevation of the study area ranges from 20 $\mathrm{m}$ to $2000 \mathrm{~m}$ above the sea level.

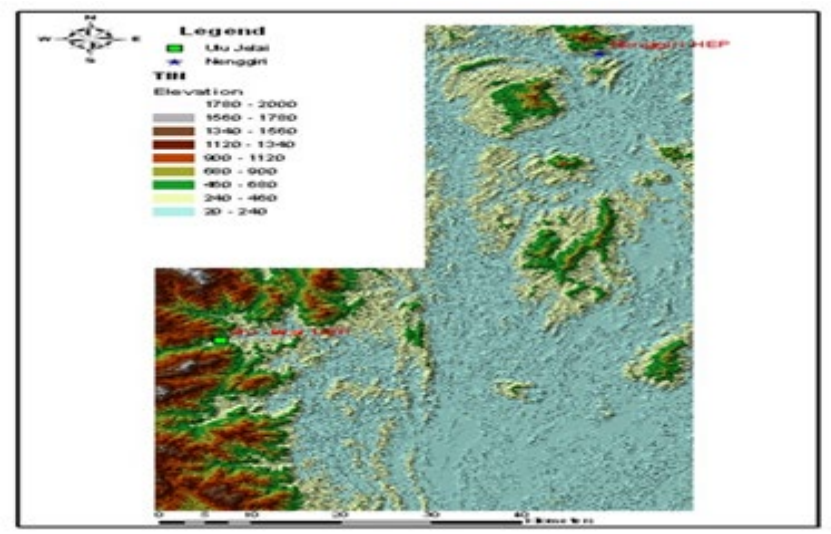

Fig. 4: Triangulate Irregular Network (TIN) for study area

This grid has 3994 rows and 1992 columns, covering the area between $389992.429986 \mathrm{~m}$ to $449752.429986 \mathrm{~m}$ Easting and $450000 \mathrm{~m}$ to $569820 \mathrm{~m}$ Northing (Fig.5). Slope map of the study area was developed from DEM. Slope of the area varies from $00^{\circ}$ to $84.4373^{\circ}$ giving the mean slope of $13.64^{\circ}$ (Fig. 6). Fig. 7 shows the Factor of Safety (FOS) map that has been generated using formula and parameter as Table 1, which the lowest FOS of area is 1.07973 as shown in Table 3.

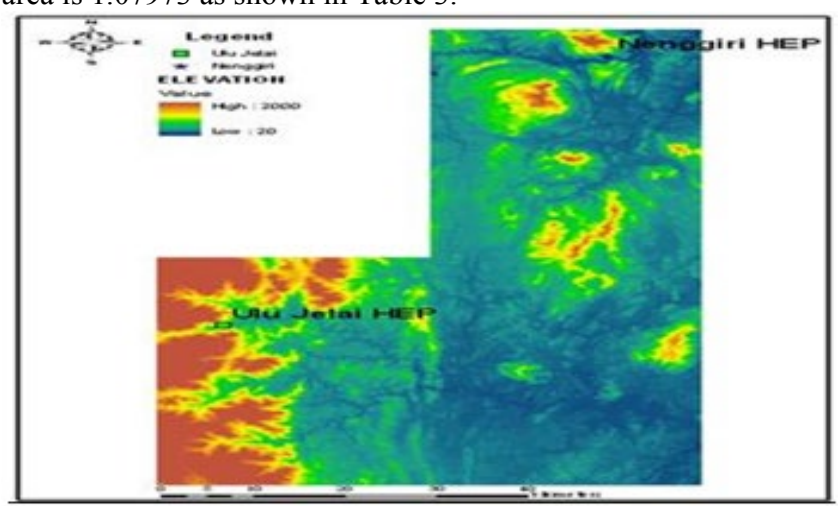

Fig. 5: Elevation Map for study area

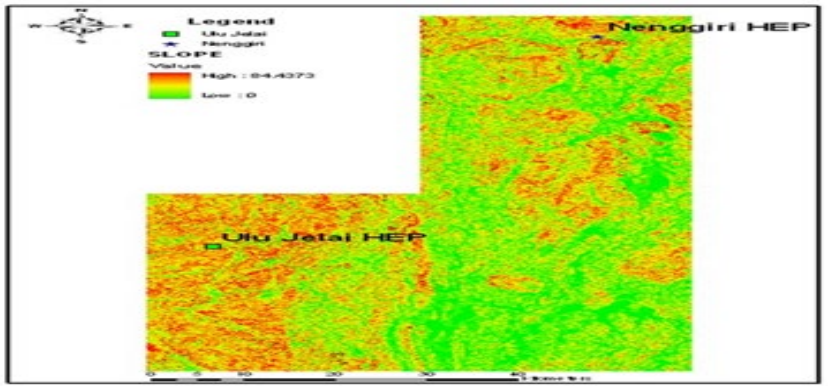

Fig. 6: Slope Map for study area

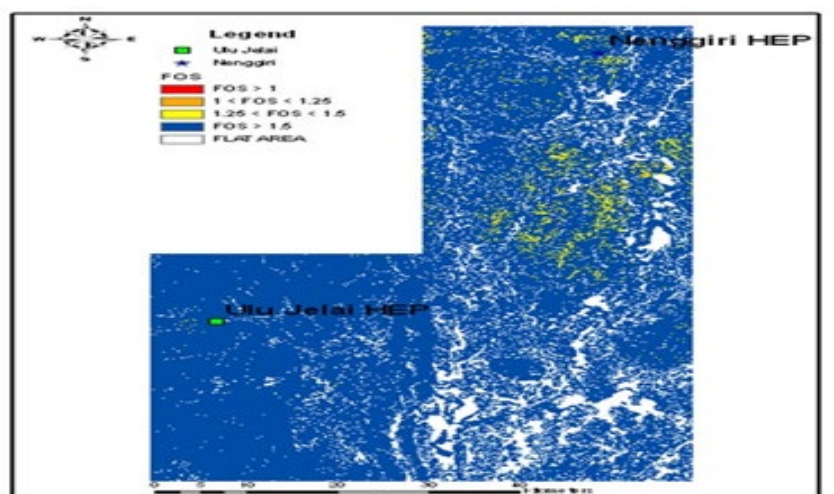

Fig. 7: Factor of Safety Map for study area

Table 4: Result of FOS generated using ArcGIS for study area

\begin{tabular}{|c|c|c|c|}
\hline Safety Factor & Slope Stability & Count & Percentage \\
\hline $1.00<$ FOS $<1.25$ & Quasi stable & 6503 & 0.08 \\
\hline $1.25<$ FOS $<1.50$ & $\begin{array}{c}\text { Moderately } \\
\text { stable }\end{array}$ & 119568 & 1.50 \\
\hline FOS $>1.50$ & Stable & 4947666 & 62.19 \\
\hline NoData/Flat Area & More Stable & 2882311 & 36.23 \\
\hline
\end{tabular}

The three alignments route generated using the GIS application fulfilled all nine (9) criteria as Table 2 and thus, the selection of the transmission line route should not be solely based on the shortest route as Fig. 8. The construction cost should be put into consideration before deciding the best transmission line route. Three costs are normally taken into account in the construction of a transmission line route, namely the wayleave, construction and survey cost.

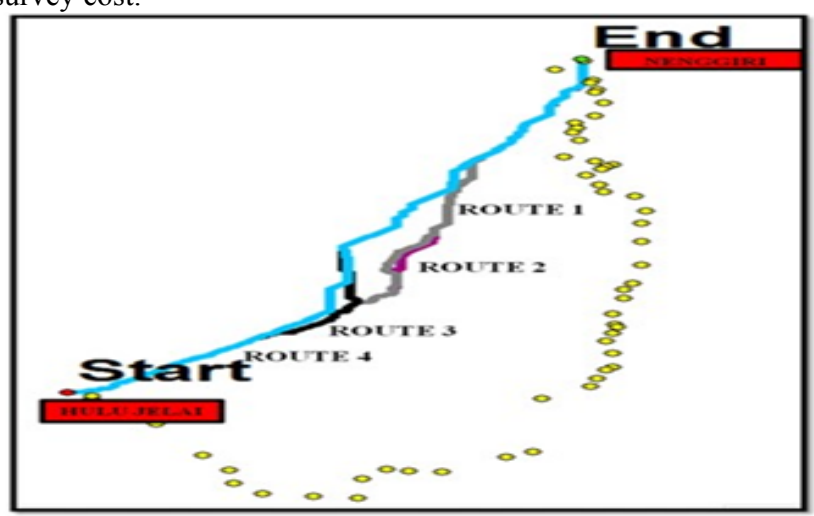

Fig. 8: Factor of Safety Map for study area

The cost comparison in these study using total cost, wayleave cost and survey cost. Fig. 9 shows the comparison of cost among the three alignments, generated by both the GIS and conventional method. The total cost using cost path technique in GIS for Alignment 1, 2 and 3 are RM 21.891 millions, RM 19.257 millions and RM 18.849 million respectively. The total costs for Alignment 1,2 and 3, generated using conventional method are RM 21.690 millions, RM 26.970 millions and RM 27.970 millions respectively. Based on the total cost comparison between the three proposed route, Route 3 required the least cost with a distance of $47 \mathrm{~km}$ followed by Route 2 with distance $47 \mathrm{~km}$ and Route 3 which required the highest cost despite being the shortest route 
among the three route. However Route 1, the alignment of the route through dense forest and require large or wide ROW.

Conventional methods shows, the total cost for Route 1 incurs the least cost compared to Route 2 and 3. This because Route 1 requires more ROW 1 chain than ROW 2 chain. ROW 1 chain is only $20 \mathrm{~m}$ wide whereby the ROW 2 chain is $40 \mathrm{~m}$ wide, double the width of ROW 1 chain, subsequently increase the land acquisition cost, survey cost and site clearing cost. Practically, ROW for transmission line going through the forest area is the ROW 2 chain, as this will protect the safety of the transmission line from the surrounding trees

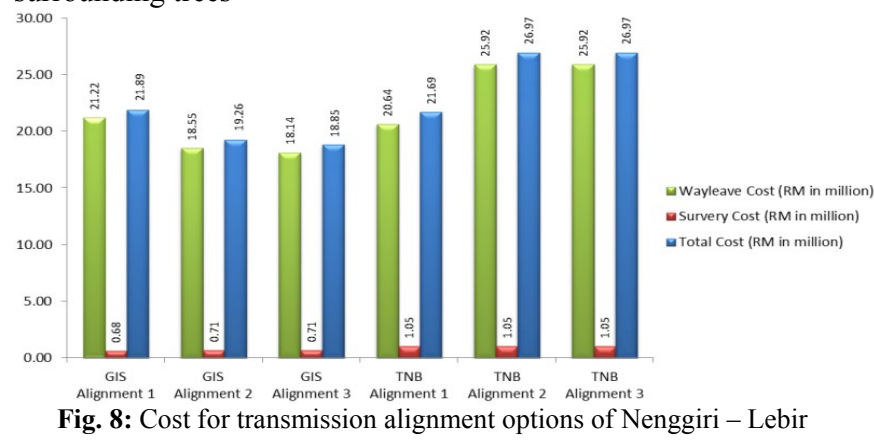

\section{Conclusion}

The GIS based analysis as applied on the present case study demonstrated that; multi-criteria approach is recognized to be used as a tool for the optimum route selection by considering different factors those affecting decision-maker selections. Furthermore, saving of money, time and effort.

\section{Acknowledgement}

This study is being supported by TNBR through Environmental Sensitive Area Route Planning 2010 and Ministry of Higher Education Malaysia through LRGS grant (01201305LRGS \& 01201307LRGS), JICA-JST for project entitled "Research and Development for Reducing Geo-Hazard Damage in Malaysia Caused by Landslide and Flood' project. Authors would like to thanks all under graduates, post graduate and research engineer that give support during site selection and installation of real time system.

\section{References}

[1] Van Westen, C.J.; Rengers, N.; Soeters, R. Use of geomorphological information in indirect landslide susceptibility assessment. Nat. Hazard. 2003, 30, 399-419.

[2] Ayalew, L.; Yamagishi, H.; Maruib, H.; Takami, K. Landslides in Sado Island of Japan: Part II. GIS-based susceptibility mapping with comparisons of results from two methods and verifications. Eng. Geol. 2005, 81, 432-445.

[3] Thiery, Y.; Malet, J.-P.; Sterlacchini, S.; Puissant, A.; Maquaire, O. Landslide susceptibility assessment by bivariate methods at large scales: Application to a complex mountainous environment. Geomorphology 2007, 92, 38-59.

[4] Yalcin, A. GIS-based landslide susceptibility mapping using analytical process and bivariate statistics in Ardesen (Turkey): Comparisons of results and confirmations. Catena 2008, 72, 1-12.

[5] Millar, J. H. \& Shaw, S. L. (2001). Geographic information systems for transportation principles and applications, Oxford University press, Inc New York 27

[6] Roy, B. \& Vanderpooten, D. (1996). The European school of MCDA,emergency basic features and current works. Journal of Multi-criteria Decision analysis, 5 pp 22-37

[7] Chakhar, S. \& Martel, J. (2003). Enhancing geographical information systems capabilities with Multi-Criteria evaluation functions. Journal of Geographic Information and Decision Analysis, 7, No. 2

[8] Geneletti, D. B. (2004). A GIS-based decision support system to identify nature conservation priorities in an alpine valley, land-use policy 21 (2004) 149-160. Retrieved August 18, 2015, from: www.elsevier.com/locate/landusepol

[9] Douglas, D H (1994), "Least cost path in GIS using an accumulated cost surface and slope lines", Cartographica, 31(3), 37-51

[10] Lee, J, D Stucky (1998), "On applying viewshed analysis for determining least-cost paths on Digital Elevation Models" International Journal of Geographical Information Science, 12, 8, pages $891-905$

[11] Dijkstra, E W (1959), "A note on two problems in connexion with graphs", Numerische Mathematik, 1, 269-271.

[12] Pinto, N., Keitt, T.H. (2009). Beyond the least-cost path: evaluating corridor redundancy using a graph-theoretic approach. Landscape Ecology 24, 253-266

[13] Fischer, G., M. Markowski, and J. Antione,(1996)," Multiple criteria land use analysis", Working Paper WP-96-006, International Institute for Applied Systems Analysis, Laxenburg, Austria

[14] Pellegrini, G.B.; Surian, N. Geomorphological study of the Fadalto landslide Venetian Prealps Italy. Landslides Eur. Union 1996, 15, 337-350.

[15] Nielsen, T.H.; Wright, R.H.; Vlasic, T.C.; Spangle, W.E. Relative Slope Stability and Land-Use Planning in the San Francisco Bay Region California; Professional Paper; U.S. Govt. Print. Off.: Washington, DC, USA, 1979.

[16]Demir, G.; Aytekin, M.; Akgün, A.; Ikizler, S.B.; Tatar, O. A comparison of landslide susceptibility mapping of the eastern part of the North Anatolian Fault Zone (Turkey) by likelihood-frequency ratio and analytic hierarchy process methods. Nat. Hazard. 2013, 65, 1481-1506.

[17] Pathak, S.; Poudel, R.K.; Kansakar, B.R. Application of Probabilistic Approach in Rock Slope Stability Analysis-An Experience from Nepal Disaster Mitigation of Debris Flows, Slope Failures and Landslides. In Proceedings of the INTERPRAEVENT International Symposium Disaster Mitigation of Debris Flows, Slope Failures and Landslides, Niigata, Japan, 25-27 September 2006; pp. 797 802.

[18] Thiebes, B.; Bell, R.; Glade, T. Deterministic Landslide Susceptibility Analysis Using SINMAP-Case Study in the Swabian Alb Germany. In Proceedings of the Conference -Geomorphology for the Futurell, Obergurgl, Austria, 2-7 September 2007; pp. 177-184.

[19]Oh, H.-J.; Lee, S.; Soedradjat, G.M. Quantitative landslide susceptibility mapping at Pemalang area, Indonesia. Environ. Earth Sci. 2010, 60, 1317-1328.

[20] Akgun, A. A comparison of landslide susceptibility maps produced by logistic regression, multi-criteria decision, and likelihood ratio methods: A case study at İzmir, Turkey. Landslides 2012, 9, 93106.

[21] Piacentini, D.; Troiani, F.; Soldati, M.; Notarnicola, C.; Savelli, D.; Schneiderbauer, S.; Strada, C. Statistical analysis for assessing shallow-landslide susceptibility in South Tyrol (south-eastern Alps, Italy). Geomorphology 2012, 151-152, 196-206.

[22] Pradhan, B.; Lee, S. Landslide risk analysis using artificial neural net-work model focusing on different training sites. Int. J. Phys. Sci. 2009, 4, 1-15.

[23] Pourghasemi, H.R.; Pradhan, B.; Gokceoglu, C. Application of fuzzy logic and analytical hierarchy process (AHP) to landslide susceptibility mapping at Haraz watershed, Iran. Nat. Hazard. 2012 63, 965-996.

[24] Arjun, C.R.; Kumar, A. Artificial neural network-based estimation of peak ground acceleration. ISET J. Earthq. Technol. 2009, 46, 19-28.

[25] Berry, J. K. (2000). Optimal path analysis and corridor routing, infusing stakeholders' perspective in calibration and weighting of model criteria. Berry \& associates spatial information system. Retrieved May 20, 2008, from: http://www.innovativegis.com

[26] Yu, C, J Lee, M J Munro Stasiuk (2003) "Extensions of least-cost path algorithms for roadway planning" International Journal of Geographical Information Science, 17, 4, pages 361-376

[27] Wang, W.-D.; Guo, J.; Fang, L.-G.; Chang, X.-S. A subjective and objective integrated weighting method for landslides susceptibility mapping based on GIS. Environ. Earth Sci. 2012, 65, 1705-1714.

[28] Frattini, P.; Crosta, G.; Carrara, A. Techniques for evaluating the performance of landslide susceptibility models. Eng. Geol. 2010, $111,62-72$.

[29] Lari, S.; Frattini, P.; Crosta, G.B. Integration of natural and technological risks in Lombardy, Italy. Nat. Hazard. Earth Syst. Sci. 2009, 9, 2085-2106. 